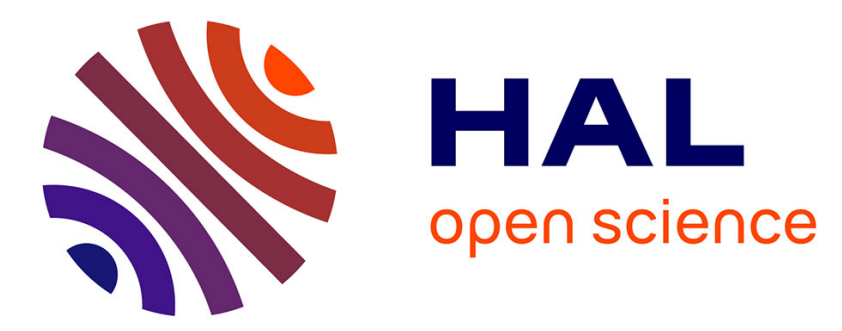

\title{
Development of a fish-based index to assess the ecological quality of transitional waters: The case of French estuaries
}

C. Delpech, A. Courrat, Stéphanie Pasquaud, Jérémy Lobry, Olivier Le Pape, D. Nicolas, Philippe Boët, Michel Girardin, Mario Lepage

\section{To cite this version:}

C. Delpech, A. Courrat, Stéphanie Pasquaud, Jérémy Lobry, Olivier Le Pape, et al.. Development of a fish-based index to assess the ecological quality of transitional waters: The case of French estuaries. Marine Pollution Bulletin, 2010, 60 (6), p. 908 - p. 918. 10.1016/j.marpolbul.2010.01.001 . hal00584047

\section{HAL Id: hal-00584047 \\ https://hal.science/hal-00584047}

Submitted on 7 Apr 2011

HAL is a multi-disciplinary open access archive for the deposit and dissemination of scientific research documents, whether they are published or not. The documents may come from teaching and research institutions in France or abroad, or from public or private research centers.
L'archive ouverte pluridisciplinaire HAL, est destinée au dépôt et à la diffusion de documents scientifiques de niveau recherche, publiés ou non, émanant des établissements d'enseignement et de recherche français ou étrangers, des laboratoires publics ou privés. 
Author-produced version of the article published in Marine Pollution Bulletin, 2010, vol. 60, n 6, p. 908 - 918 The original publication is available at http://www.sciencedirect.com/ doi : 10.1016/j.marpolbul.2010.01.001

1 Development of a fish-based index to assess the ecological quality of transitional waters: the case of French estuaries.

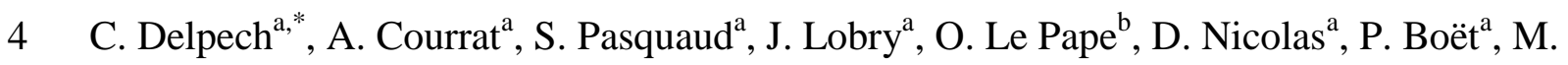

5 Girardin $^{\mathrm{a}}$, M. Lepage

6

$7{ }^{a}$ Cemagref (French Institute of Agricultural and Environmental Engineering Research), 50

8 avenue de Verdun, B.P. 3, 33612 Cestas Cedex, France

$9{ }^{b}$ Université Européenne de Bretagne, UMR 985 Agrocampus Ouest, Inra « Ecologie \& Santé

10 des Ecosystèmes », Ecologie halieutique, Agrocampus Rennes, 65 rue de St Brieuc, CS 84215,

1135042 Rennes, France

12

$13 *$ Corresponding author.

14 E-mail address: christine.delpech@cemagref.fr 
Author-produced version of the article published in Marine Pollution Bulletin, 2010, vol. 60, n 6, p. 908 - 918

The original publication is available at http://www.sciencedirect.com/

doi : 10.1016/j.marpolbul.2010.01.001

\section{Abstract}

The Water Framework Directive requires the assessment of the ecological status of

transitional waters considering the fish component. An original methodology, based on a

pressure-impact approach, was established to develop a multimetric fish-based index to

21 characterize the ecological quality of French estuaries. An index of contamination, based on

22 the chemical pollution affecting aquatic systems, was used as a proxy of anthropogenic

23 pressure. The fish metric selection was based on their response to disturbances tested via

24 statistical models (generalized linear models) taking into account sampling strategy and

25 estuarine features. Four metrics, for which discriminating responses to level of pressure were

26 demonstrated, were retained to constitute the estuarine multimetric fish index. This new tool

27 appeared particularly relevant to detect the contamination effects on fish communities in

28 estuaries. It could help managers to take decisions in order to maintain or reach the good

29 status required by the Water Framework Directive for 2015.

30

31 Keywords: multimetric fish index, anthropogenic disturbances, ecological quality status,

32 estuaries, generalized linear models 
Author-produced version of the article published in Marine Pollution Bulletin, 2010, vol. 60, n 6 , p. 908 - 918 The original publication is available at http://www.sciencedirect.com/ doi : 10.1016/j.marpolbul.2010.01.001

\section{Introduction}

Transitional waters ${ }^{1}$ are highly variable environments. They are influenced by fluctuating marine and freshwater flows, which lead to large and quick variations of their physicochemical features. By providing many species with basic requirements for their life cycle, these particular areas support a wide range of fauna, from resident to freshwater and marine species. Estuaries are especially essential to fish due to their ecological functions related to refuge area, habitats for reproduction, permanent habitat, nursery grounds and migration routes (Elliott et al., 2007). However, they are impacted by multiple anthropogenic disturbances such as fishing, dredging, pumping and pollution (Blaber et al., 2000; Cloern, 2001; Dauvin, 2008).

In this context, the assessment of the ecological status of transitional waters is required, especially in the European Union (EU Water Framework Directive; WFD - Directive 2000/60/EC; Anonymous, 2000). Fish communities appear to be a relevant biological element to evaluate aquatic ecosystems' health (Karr, 1981; Karr et al., 1986; Elliott et al., 1988; Fausch et al., 1990; USEPA, 2000; Whitfield and Elliott, 2002; Harrison and Whitfield, 2004). Several types of indices exist: some are based on only one criterion as the Community Degradation Index (CDI; Ramm, 1988) and the Biological Health Index (BHI; Cooper et al., 1994), while others consist of a combination of several metrics, i.e. the Indices of Biotic Integrity (IBI; Karr, 1981; Roset et al., 2007). A metric is defined as "a measurable factor that represents various aspect of biological assemblage, structure, function, or other community component" (USEPA, 2000; Coates et al., 2007). Thus, multimetric indices are expected to provide information about various aspects of fish assemblages and lead to a more holistic, integrative and functional approach (Roset et al., 2007).

\footnotetext{
${ }^{1}$ surface waters in the vicinity of river mouths, partly saline in character as a result of their proximity to coastal waters but substantially influenced by freshwater flows (WFD - Directive 2000/60/EC)
} 
Author-produced version of the article published in Marine Pollution Bulletin, 2010, vol. 60, n 6, p. 908 - 918 The original publication is available at http://www.sciencedirect.com/

doi : 10.1016/j.marpolbul.2010.01.001

58 Based on fish data for 13 estuaries in France, the aim was here to develop a multimetric fishbased index to assess the ecological status of French estuaries, as required by the WFD. Fish metrics were constructed using ecological guilds (Elliott and Dewailly, 1995). Their response to anthropogenic pressures was analysed, taking into account the effects of the sampling design (Mouillot et al., 2006). Then a selection was realised based on the ability of these metrics to discriminate between different levels of pressure. Last, selected metrics were combined to develop a multimetric index of estuarine ecological status (Roset et al., 2007).

\section{Materials and methods}

67

\subsection{Fish data}

Thirteen estuaries along the French Atlantic and English Channel coasts were sampled in 2005 and 2006 (Fig. 1) following a standardised sampling protocol (Lepage and Girardin, 2006). The fishing events occurred in Spring and Autumn. Two types of beam trawls were used according to the size of estuaries. One had an opening of $3 \times 0.5 \mathrm{~m}$ and a $20 \mathrm{~mm}$ stretched mesh in the codend and was used in large estuaries only; the other had an opening of $1.5 \times 0.5 \mathrm{~m}$ and $16 \mathrm{~mm}$ stretched mesh in the codend and was preferred in small estuaries. Trawling was performed during daytime, against the current, for about $15 \mathrm{~min}$ at a speed ranging from 1.5 to 3 knots. The number of trawl hauls ranged from 12 to 78 per estuary and per season (Table 1). Hauls were distributed, as far as possible, all along the salinity gradient inside the estuaries but obvious sewage points were avoided when known. All fishes caught were identified, measured and counted. After each fishing event, salinity was recorded. This

81 dataset included 734 trawl hauls. 
Author-produced version of the article published in Marine Pollution Bulletin, 2010, vol. 60, n 6, p. 908 - 918 The original publication is available at http://www.sciencedirect.com/

doi : 10.1016/j.marpolbul.2010.01.001

\subsection{General methodology}

The lack of pristine sites and historical data to establish reference conditions as required by the WFD, led us to adopt a methodology based on statistical modelling (Pont et al., 2006): thresholds and reference points were defined using pressure/impact models (DPSIR approach - Borja et al., 2006). A first approach based on such models showed the negative impact of proxies of anthropogenic disturbances on the nursery function of estuaries for marine fish species (Courrat et al., 2009). This work highlighted the need to take into account the variability in fish metrics due to the sampling protocol and some estuarine features, as they represented a great part of the variability in fish data (Nicolas et al., In press). This method appeared particularly appropriate in a context of « Estuarine Quality paradox », i.e. when the effects of natural and anthropogenic stress on estuarine biota are difficult to discriminate (Elliott and Quintino, 2007; Dauvin and Ruellet, 2009). Hence, in order to build a multimetric fish based index for French transitional waters, we adopted the following steps (Fig. 2): (1) Indices based on human pollutions and activities were elaborated to describe the anthropogenic disturbances that potentially affect fishes. (2) Candidate fish metrics were selected with regard to literature and previous knowledge. (3) The impact of overall contamination on candidate metrics was tested via statistical modelling. The models were realized at the trawl haul sampling scale and took into account the variability due to sampling

102 protocol and environmental features. (4) Metrics whose response to pressure was significant

103 were selected. (5) A methodology was developed to calculate thresholds distinguishing

104 between three levels of contamination. (6) Redundant metrics and metrics with non-

105 discriminant thresholds were removed. (7) Scores (1-3-5) were attributed by comparing 106 metric values, calculated from the survey data, to the above-mentioned thresholds according 
Author-produced version of the article published in Marine Pollution Bulletin, 2010, vol. 60, $n^{\circ} 6$, p. 908 - 918 The original publication is available at http://www.sciencedirect.com/

doi : 10.1016/j.marpolbul.2010.01.001

to spatio-temporal conditions of sampling and estuarine features. (8) These scores were combined to provide a general assessment of the ecological status of each estuary. (9) A comparison between levels of pressure and multimetric scores was realized.

\subsection{Candidate metrics}

Candidate fish metrics were selected to characterize both fish diversity and the various ecological functions associated with transitional waters. The global diversity, described by the taxonomic richness, i.e. the number of species caught, and the total density were considered. A review of existing studies (Claridge et al., 1986; Elliott et al., 1990; Pomfret et al., 1991; Elliott and Dewailly, 1995; Deegan et al., 1997; Marshall and Elliott, 1998; Cabral et al., 2001; Thiel and Potter, 2001; Lobry et al., 2003; Thiel et al., 2003; Breine et al., 2004; Coates et al., 2004; Harrison and Whitfield, 2004; Maes et al., 2005; Breine et al., 2007; Elliott and Quintino, 2007) led us to focus on a guild approach to characterize the functional aspects of transitional waters for fish. Root (1967) defined a guild as a group of species that exploit the same class of environmental resources in a similar way. We used an extended definition to include a description of the way species use transitional waters, as well as their feeding mode and their vertical distribution in the water column (Elliott and Dewailly, 1995; Lobry et al., 2003; Franco et al., 2006; Elliott et al., 2007; Table 2). All fish species present in the dataset were classified for each type of guild. Number of species and density were selected as potential metrics and calculated for each guild. In the aim of assessing estuaries' ecological status, the retained metrics were supposed to have significant trends with increasing degradation (Breine et al., 2004; Breine et al., 2007). Thus, for each metric, the expected response with increasing degradations was defined according to literature and expert's 
Author-produced version of the article published in Marine Pollution Bulletin, 2010, vol. 60, $n^{\circ} 6$, p. 908 - 918

The original publication is available at http://www.sciencedirect.com/

doi : 10.1016/j.marpolbul.2010.01.001

131 judgements and only the metrics known to negatively respond to increasing anthropogenic

pressures were retained (Table 3).

\subsection{Modelling for the fish metrics}

136 All metrics were modelled at the trawl haul scale (one trawl haul = one line in the dataset) to

137 take into account the metrics' variability due to sampling protocol (Courrat et al., 2009).

138 Each fish metric was modelled with Generalized Linear Models (GLMs) using R software (R

139 Development Core Team, 2005).

140 Models options depended on data distribution for the different metrics. For species richness

141 (SR), global and by guilds, the GLMs were based on a Poisson law:

$142 \log (\mathrm{SR}) \approx$ constant + variable $_{1}+$ variable $_{2}+\ldots+$ variable $_{\mathrm{n}}$

143 where variable[1,2,.,n] represents the introduced descriptors that can be either continuous

144 covariates or class factors.

145 The metrics expressed in density were composed of 0 inflated data, which made inappropriate

146 the use of linear models. Thus, a delta type model that consisted in a combination of two

147 models was used (Stefansson, 1996). The first was a binomial model on the presence-absence

148 data $\left(\mathrm{D}_{0 / 1}\right)$.

$149 \operatorname{Logit}\left(\mathrm{D}_{0 / 1}\right) \approx$ constant + variable $_{1}+$ variable $_{2}+\ldots+$ variable $_{\mathrm{n}}$

150 The second model tested the positive densities $\left(\mathrm{D}_{+}\right)$which were log-transformed using a

151 Gaussian law (Le Pape et al., 2003; Nicolas et al., 2007; Courrat et al., 2009):

$152 \log \left(\mathrm{D}_{+}\right) \approx$ constant + variable $_{1}+$ variable $_{2}+\ldots+$ variable $_{\mathrm{n}}$ 
Author-produced version of the article published in Marine Pollution Bulletin, 2010, vol. 60, n 6, p. 908 - 918 The original publication is available at http://www.sciencedirect.com/

doi : 10.1016/j.marpolbul.2010.01.001

157 Courrat et al. (2009) highlighted the importance of descriptors of the sampling protocol and

158 estuarine features to explain the variability of the number of species and the abundances of

159 marine juvenile migrants in French estuaries. The present work is based on an extrapolation

160 of these results to other metrics. The models estimated species richness and fish densities in

161 different guilds at the sampling scale; while taking into account some factors describing

162 protocol variability and environmental/hydromorphologic features, they analysed the effects

163 of anthropogenic pressures on these metrics.

164

\subsubsection{Variables for the description of the effect of the sampling protocol on fish metrics}

166 Fish assemblages in transitional waters change according to seasons (Elliott et al., 1990;

167 Araùjo et al., 1998; Thiel et al., 2003; Koutrakis et al., 2005; Franco et al., 2006; Lobry et al.,

168 2006), hence the effect of sampling season (spring or autumn) was tested as a class factor.

169 Transitional waters are characterized by a strong salinity gradient, known to have a significant

170 effect on fish assemblages (Thiel et al., 1995; Marshall and Elliott, 1998; Lobry et al., 2006;

171 Franco et al., 2008b). Salinity was tested within models as a class factor. Salinity class

172 boundaries were adapted from the Venice system (1958): oligohaline class ([0-5]),

173 mesohaline class (]5-18]) and polyhaline class (>18).

174

175 2.5.2. Variable for the description of the effect of environmental and hydromorphologic

176 features at a larger scale on fish metrics

177 As French coasts of Atlantic and English Channel sheltered different fish assemblages

178 (Coates et al., 2004; Franco et al., 2008a), an ecoregion factor was also taken into account in

179 the models. 
Author-produced version of the article published in Marine Pollution Bulletin, 2010, vol. 60, n 6, p. 908 - 918 The original publication is available at http://www.sciencedirect.com/

doi : 10.1016/j.marpolbul.2010.01.001

180 Estuarine size has been pointed out as a significant predictor of taxonomic richness (Monaco et al., 1992; Elliott and Dewailly, 1995; Roy et al., 2001; Nicolas et al., In press). Thus, the and the small estuaries with the small one (except for the Loire estuary which was sampled with the small gear in its oligohaline area), estuarine size and type of beam trawl were strongly correlated, which induced redundancy in the models. One of these two variables has to be removed. Hence, the variable "size of estuary", replaced the variable "type of beam trawl" used by Courrat et al. (2009) as, in the context of the WFD requirements, it appears more consistent to define thresholds varying according to water bodies' physical

190 characteristics.

\subsection{Indices of anthropogenic pressures}

An index of contamination was used as a proxy for human disturbances impacting estuaries.

We used data on the chemical contamination collected by the French monitoring network of the marine environment (RNO; www.ifremer.fr/envlit). All 13 estuarine areas considered in this study correspond to sites investigated by this network. Concentrations of five heavy metals $(\mathrm{Cd}, \mathrm{Zn}, \mathrm{Cu}, \mathrm{Hg}$ and $\mathrm{Pb}$ ) and two organic pollutants (polychlorobiphenyle and polycyclic aromatic hydrocarbons) in two mollusc species (mussels Mytilus edulis and oysters Crassostrea gigas) were standardized (Beliaeff et al., 1998; Gilliers et al., 2006). For each

201 site, median values were computed over 6 years: from 2000 to 2005. Medians were preferred to means because they are more robust with regard to outliers (Beliaeff et al., 1998). A normed Principal Component Analysis (PCA) was computed to synthesize the number of

204 variables (contaminants, in column) used to describe the overall chemical contamination of 
Author-produced version of the article published in Marine Pollution Bulletin, 2010, vol. 60, $n^{\circ} 6$, p. 908 - 918

The original publication is available at http://www.sciencedirect.com/

doi : 10.1016/j.marpolbul.2010.01.001

the sites (individuals, in row). This PCA allowed to compute two distinct indices of

contamination (Courrat et al., 2009): the first axis was strongly influenced by the metals

whereas the second axis was related to the organic pollutants. Hence, an index of heavy metal

pollution and an index of organic pollution were derived from the factorial scores of the

estuaries along each axis. Finally, the index of overall contamination (used in models as a

proxy of the cumulative effects of human disturbances in estuaries) was obtained by summing

211 the scaled values (factorial scores) of the first two indices (Fig. 3).

\subsection{Statistical analyses}

The models, including effects of protocol (salinity class, season), estuarine features

216 (ecoregion, estuarine size) and anthropogenic pressure proxy, can be written as follows:

Metric $\approx$ factor(season $)+$ factor(salinity $)+$ factor(size $)+$ factor(ecoregion $)+$

covariate(contamination index)

"Correlating the results of a metric to the stressor gradient is a central part of the procedure"

(Hering et al., 2006). We calculated the statistical significance of each descriptor and pressure index effect at the level of 5\% in GLMs (Chi-squared test). The non-significant descriptors were removed from the models. The nature (positive or negative) of the impact of each variable and of the pressure index on the fish metrics was determined from the sign of the corresponding coefficient(s). A graphical analysis of the residuals was carried out for each

226 GLM to verify underlying hypotheses.

\subsection{Metric selection}


Author-produced version of the article published in Marine Pollution Bulletin, 2010, vol. 60, n 6, p. 908 - 918 The original publication is available at http://www.sciencedirect.com/

doi : 10.1016/j.marpolbul.2010.01.001

The checkout of initial hypotheses concerning the expected trends of the metrics with

increasing degradation is an essential step to build multimetric indices (Roset et al., 2007). A

metric (density or species richness, global or by guild) was retained only when the initial

hypothesis of its trend with increasing anthropogenic disturbances was confirmed by models.

A second selection consisted in testing the correlations (Pearson correlation test) between each pair of metrics. When two metrics were strongly correlated, only one was kept to avoid redundancies.

\subsection{Test of discriminance in response to pressure and thresholds calculation}

Thresholds were established using fitted values from the GLMs and corresponding confidence intervals. For each selected metric, a model was constructed with a combination of the significant variables among season, salinity class, estuarine size and ecoregion. Then fitted values of these models were calculated for 3 levels of anthropogenic pressure. In the studied estuaries, the highest value of the overall contamination index was found in the Seine estuary and the lowest in the Mont Saint Michel Bay (Fig. 3); these values were used to respectively simulate high and low pressure. Then the mean of these two extreme values was used to characterize an intermediate level of pressure.

To define confidence intervals, we simulated 5000 virtual observations for the different models (glm Poisson) and submodels (glm Binomial and glm Gaussian), with means equal to

250 the corresponding predicted values and standard deviation equal to corresponding predicted 251 standard errors. For metrics of densities, the 5000 simulated probabilities of presence and the 2525000 simulated log-densities were then multiplied to produce 5000 simulated densities.

253 Finally, for each metric, the $10 \%$ and $90 \%$ quantiles of the 5000 simulated densities or 254 number of species were used as confidence intervals. 
Author-produced version of the article published in Marine Pollution Bulletin, 2010, vol. 60, n 6, p. 908 - 918 The original publication is available at http://www.sciencedirect.com/

doi : 10.1016/j.marpolbul.2010.01.001

Thresholds were defined by considering the gap between the confidence intervals around the predicted value obtained for the 3 simulated levels of pressure. The thresholds were expressed as numbers of species for the metrics related to species richness and as log-densities for the metrics of total density or density per guild. Hence, for each metric discriminating between the three levels of pressure, two thresholds distinguishing three quality classes were calculated according to the protocol and environmental conditions (Fig. 4a). However, when the confidence intervals overlapped for most of the combinations of natural variables, we considered that the risk of uncertainty was too high and we decided not to maintain the metric into the multimetric index (Fig. 4c); when confidence intervals only overlapped under certain conditions, the metric was kept (Fig. 4b).

\subsection{Scoring}

For each metric, the value calculated from the dataset was compared to the thresholds defined previously to estimate scores (Roset et al., 2007). A score was attributed only if the number of hauls realised for the corresponding season and salinity class was considered as sufficient to provide a reliable representation of the fish metric. Some preliminary analyses (unpublished data) based on bootstrapping on a pool of virtual trawl hauls generated by the models were made in order to determine what is this "sufficient" number of trawl hauls. Though these analyses have still to be improved, results tend to show that with 6 trawl hauls, it is possible to get an assessment of fish densities with an acceptable error, which means that this error does not lead to a misclassification of the salinity class ecological status. Here it was thus assumed that 6 trawl hauls per salinity class and per season may allow to assess accurately the ecological status of a salinity class.

A score equal to (Fig. 4): 
Author-produced version of the article published in Marine Pollution Bulletin, 2010, vol. 60, $n^{\circ} 6$, p. 908 - 918

The original publication is available at http://www.sciencedirect.com/

doi : 10.1016/j.marpolbul.2010.01.001

$280-1$ was attributed if the metric value was situated below the prediction realized for the

281 maximum of pressure i.e. the worst class of quality,

$282-3$ was attributed if the metric value was situated between the predictions for the 2 levels of

283 pressure i.e. the class of moderate quality,

$284-5$ was attributed if the metric value was situated above the prediction for the minimum of

285 pressure i.e. the best class of quality.

286 When the $10 \%$ and $90 \%$ quantiles of two consecutive levels of pressure overlapped, a score of

2872 or 4 was attributed for the metric values situated into the uncertainty area (Fig. 4b).

288 The scores obtained for each season and each salinity class were added and divided by the

289 maximal potential score ( $5 \mathrm{x}$ number of summed scores) to get one value for each metric and

290 each estuary. These values per metric were then averaged to get the final value of the

291 multimetric index for each estuary.

292 Finally, a linear regression was performed to test the relevance of the final multimetric fish

293 index regarding the increasing index of contamination.

295 3. Results

\subsection{Metric selection}

299 Freshwater and fish feeder species were absent in more than $90 \%$ of the trawl hauls, so

300 modelling for them was irrelevant. The models testing the effect of the pollution index are

301 described in Table 4. The descriptors of the protocol and the environmental features were

302 significant for most of the metrics and they partly explained their variability. 11 metrics

303 showed significant trends with increasing pressure, 10 being negative (Table 4 ) thus identical 
Author-produced version of the article published in Marine Pollution Bulletin, 2010, vol. 60, n 6, p. 908 - 918

The original publication is available at http://www.sciencedirect.com/

doi : 10.1016/j.marpolbul.2010.01.001

\subsection{Multimetric index values} ecoregion).

\subsection{Discriminance of metrics with regard to different levels of anthropogenic disturbances}

The $10 \%$ and $90 \%$ quantiles of two consecutive levels of pressure overlapped for all the metrics expressed in number of species (Table 4). Thus, these metrics were considered as irrelevant for assessing the ecological status of French estuaries with the present approach. The quantiles also overlapped for the densities of diadromous and marine juveniles in the small Atlantic estuaries. Nevertheless, these metrics were maintained into the multimetric index, as the uncertainty area was limited to specific conditions.

Finally, four metrics were retained: total density (TD), density of diadromous migrant species (DDIA), density of marine juvenile migrants (DMJ) and density of benthic species (DB) (Table 4). For each of them, thresholds between different levels of contamination were calculated for the different combination of factors (season, salinity class, estuarine size, 
Author-produced version of the article published in Marine Pollution Bulletin, 2010, vol. 60, n 6, p. 908 - 918 The original publication is available at http://www.sciencedirect.com/

doi : 10.1016/j.marpolbul.2010.01.001

According to comparisons between in situ data and thresholds (Fig. 4), scores were attributed

for each fish metric in each combination of factor describing sampling protocol and estuarine features; then these scores were combined in a multimetric index value for each estuary. For the 13 Atlantic and English Channel estuaries, the multimetric fish index values ranged from 0.26 in the Gironde estuary to 0.95 in the Mont St Michel Bay (Fig. 5). A linear regression showed a significant negative relationship $\left(r^{2}=0.35\right.$, p.value $\left.<0.05\right)$ between this estuarine multimetric fish index and the index of contamination (Fig. 6).

\section{Discussion}

This paper presents the development of a fish-based index for defining the ecological status of transitional waters using a pressure/impact approach. The methodology is in agreement with

340 the processes recommended by Hering et al. (2006) and Stoddard et al. (2008) for the creation

341 of multimetric indices. Despite the 'estuarine quality paradox', i.e. the fact that features of 342 anthropogenic stress coincide with those of natural stress in estuaries (Elliott and Quintino, 343 2007), we showed significant relationships between anthropogenic disturbances and various 344 aspects of fish assemblages. Thresholds were identified for metrics presenting significant 345 trends with increasing pressure and a system of scoring was elaborated to qualify estuaries' 346 quality by combining the selected fish metrics.

\subsection{Pressure index}

The anthropogenic pressure index used - i.e. index of contamination - focuses on only one 
Author-produced version of the article published in Marine Pollution Bulletin, 2010, vol. 60, n 6, p. 908 - 918 The original publication is available at http://www.sciencedirect.com/

doi : 10.1016/j.marpolbul.2010.01.001

estuaries. The data used for this work were the most precise and homogenous data that corresponded to the present fish sampling period. It would be fruitful to improve this pressure index especially considering hydromorphological modifications like polderisation and loss of intertidal mudflat leading to loss of habitat. In the present study, the index of contamination was used as proxy for the overall anthropogenic disturbances impacting these estuaries (Courrat et al., 2009). Aubry and Elliott (2006) qualified these indicators of disturbance in their contribution to the development of the Environmental Integrative Indicators, as "potential", because (i) the process of the biological response to an increase of this measure of pressure was not demonstrated here, even if they are known from previous approaches (Courrat et al., 2009) (ii) the measure of pressure did not take into account the whole anthropogenic disturbances.

\subsection{A general method to test the effect of anthropogenic pressure with regard to other sources of variability}

The degree of spatial and temporal variability in transitional waters is high (McLusky, 1981) and previous studies emphasised the need to take into account the effects of sampling protocol and estuarine features on fish metrics (Whitfield and Elliott, 2002; Mouillot et al., 2006;

Roset et al., 2007; Courrat et al., 2009). The present study confirmed that fish metrics highly depend on sampling and that it is necessary to consider these metrics at the sampling site scale in estuaries' status assessment to take into account the patterns of natural variations. On the contrary, designing fish metrics at the scale of the estuary would restrict the analysis to the number of sampled systems (here: 13) and would lead to use very simple models, few synthetic descriptors and spurious approach to take into account differences in sampling protocol. In conclusion, the effects of the sampling design cannot be summarized at the scale 
Author-produced version of the article published in Marine Pollution Bulletin, 2010, vol. 60, $n^{\circ} 6$, p. 908 - 918 The original publication is available at http://www.sciencedirect.com/

doi : 10.1016/j.marpolbul.2010.01.001

of estuary, making the use of fish metrics at this scale for testing anthropogenic disturbance effects irrelevant (Courrat et al., 2009). This conclusion is essential to assess ecological quality, as a non-accurate description of the natural variability can hamper the sensitivity of fish indices to human disturbance (Roset et al., 2007). Furthermore, working at the sampling scale will allow for testing the effects of other descriptors linked to intra-estuarine variability. Moreover, in the aim of monitoring estuarine quality, this approach could allow to estimate different ecological status in different part of a system, at least along an upstream downstream salinity gradient.

A large part of the metric variability was not explained by the models used in this study (from 65 to $82 \%$ ). The addition of more environmental variables likely to influence estuarine fish assemblages can improve the interpretation of the metric variability. Especially, further descriptors of habitat richness and diversity, in addition to the single description of estuarine size, could improve models accuracy. However, this would complicate the calculation of thresholds and the scoring process by increasing the number of combinations of factors describing estuarine features to account for in the statistical predictions. Furthermore, the WFD requires a limited number of thresholds. An exhaustive list of all the environmental factors affecting fishes can not be included in models. The present approach was a balance between available exhaustive descriptors, models parsimony and limited complexity in threshold calculation. In spite of a large residual variability, this approach provides a simple and robust method to estimate fish metric levels with regard to estuaries' quality. 
Author-produced version of the article published in Marine Pollution Bulletin, 2010, vol. 60, n 6, p. 908 - 918 The original publication is available at http://www.sciencedirect.com/

doi : 10.1016/j.marpolbul.2010.01.001

Among the 16 candidate metrics, 10 were found to respond significantly to anthropogenic pressure in the expected direction. Species richness and fish densities are usually considered as good indicators for ecological status of estuaries (Hughes et al., 1982). Most of the selected metrics describe the structure of fish assemblages using the concept of guilds. The guild approach has been recognized to be a good scheme to describe and explain transitional waters' community structure and estuarine functionalities (Deegan et al., 1997; 2004; Coates et al., 2004; Harrison and Whitfield, 2004; Breine et al., 2007; Elliott et al., 2007; Franco et al., 2008a; Franco et al., 2008b). Moreover, in such inter-site studies, it allows to overcome the differences in fish assemblages through geographical gradients and to obtain robust indices (Mouillot et al., 2006).

\section{Metrics of species richness}

Species richness usually decreases with a decrease of the habitat quality (Hughes et al., 1982; Gibson, 1994). Here, fish species richness appeared to significantly decrease when anthropogenic pressure is enhanced. This has been verified on the global species richness and also per guild. Thus, anthropogenic disturbances appeared to have significant negative effects on almost all metrics of species richness.

\section{Metrics of fish density}

The metric of total density was selected for the multimetric fish index. The total density appeared to be a common surrogate for system productivity and a good element to evaluate ecosystem health (Karr, 1981; Deegan et al., 1997). Moreover, metrics of global abundances satisfy the WFD (Anonymous, 2000) which asks to monitor composition and abundance for fish in transitional waters.

Several metrics related to density per guilds were also retained: 
Author-produced version of the article published in Marine Pollution Bulletin, 2010, vol. 60, $n^{\circ} 6$, p. 908 - 918 The original publication is available at http://www.sciencedirect.com/ doi : 10.1016/j.marpolbul.2010.01.001

- density of diadromous migrant species. Diadromous migrants use transitional waters as migration routes (Deegan et al., 1997; Roth et al., 1998; Oberdorff et al., 2002; Levrel, 2007) and are highly sensitive to many sources of pollution and degradation, particularly to migration barriers, which make this metric an important indicator of connectivity (McDowall and Taylor, 2000; Elliott and Hemingway, 2002).

- density of marine juvenile migrants. Many studies have demonstrated the negative effect of anthropogenic degradations on marine juveniles and the nursery function of the estuaries (Gibson, 1994; Deegan et al., 1997; Gilliers et al., 2006; Breine et al., 2007; Le Pape et al., 2007) and Courrat et al. (2009) focused on this guild with the same data to develop the present approach.

- density of benthic and benthivorous fish. Benthic species are particularly sensitive to siltation and oxygen deficiency (Oberdorff and Porcher, 1994; Kestemont et al., 2000) and are considered as early-warning indicators of anthropogenic disturbance (Hughes et al., 1998). This metric appeared particularly interesting to assess the degree of perturbation of benthic habitats and has already been used in other multimetric index (Borja et al., 2004; Breine et al., 2004; Coates et al., 2004; Harrison and Whitfield, 2004; Uriarte and Borja, 2009). Benthic feeders were shown to respond negatively to anthropogenic pressure but their redundancy with benthic species led to the removal of this metric from the final index. Even if trophic guild metrics should be interesting tools to characterize ecological function of estuaries (Elliott and Dewailly, 1995) as they provide an insight into the community structure (Hughes et al., 1982), none was retained in the final index.

The aim of the present approach was to analyse the response of fish metrics, considered as relevant to estimate the ecological status of estuaries, to potential indicators of disturbance (Aubry and Elliott, 2006) based on chemical contamination (Courrat et al., 2009). It 
Author-produced version of the article published in Marine Pollution Bulletin, 2010, vol. 60, n 6, p. 908 - 918 The original publication is available at http://www.sciencedirect.com/

doi : 10.1016/j.marpolbul.2010.01.001

highlighted the negative impact of a proxy of anthropogenic pressures on different metrics representing ecological and functional integrity of estuaries. Even if, for some metrics, the effect was not significant (and even opposite to expected for positive densities of marine seasonal species), the methodology developed by Courrat et al. (2009) for the marine juveniles appears efficient to test the effects of anthropogenic pressures on other fish metrics and can be extrapolated to other components of the fish structure.

\subsection{The multimetric fish index}

\subsubsection{Thresholds}

Two thresholds, separating 3 classes, have been calculated from 3 levels of anthropogenic disturbance. The lower and the upper levels are associated with the best and the worst status observed among the sampled sites. This could correspond to good and poor status referring to the WFD terminology. No site corresponds to pristine site (high status) or to heavily disturbed site (bad status). Extrapolations from model's predictions below or up to the observed level of contamination could allow to assess metric values in reference situation, as it has already been realized with the method of quintiles or the Maximum Value Lines (Oberdorff and Hughes, 1992; Oberdorff et al., 2001; Harrison and Whitfield, 2004; Breine et al., 2007; Coates et al., 2007).

Among the 10 metrics presenting a significant response in the expected direction, four were finally selected for the estuarine multimetric index. All these metrics are expressed in density. Although metrics expressed in number of species decreased significantly with anthropogenic pressure, developing thresholds was not realistic because of overlapping quality class intervals. This is the consequence of the low number of species caught per sample: it is difficult to discriminate between quality statuses if the expected number of species per sample 
Author-produced version of the article published in Marine Pollution Bulletin, 2010, vol. 60, $n^{\circ} 6$, p. 908 - 918 The original publication is available at http://www.sciencedirect.com/

doi : 10.1016/j.marpolbul.2010.01.001 in each guild is low. This is called by Hering et al. (2006) "the numerically unsuitable metrics". Further approaches would have to be tested in the future to include species richness in the indicators (Nicolas et al., In press).

Nevertheless, our approach reached reliable estimates and was able to distinguish different levels of disturbances (Quataert et al., 2007). This method implies a large enough sampling survey, well distributed on the whole transitional area. Such standardization is essential to provide consistency in the assessment based on fish indices (Roset et al., 2007).

\subsubsection{Combining metrics in a composite index}

The multimetric fish index provided relatively accurate classification of the estuaries. Indeed, the Gironde and Seine estuaries obtained the lowest values concerning fish aspect and were also the most perturbed in agreement with our proxy based on chemical contamination but also with expert knowledge. Conversely, the Mont Saint Michel Bay and the Charente estuary, where the perturbation index is low, presented high scores for the multimetric fish index. A significant negative correlation was found between the level of contamination and the fish index. However, the explained percentage of variability was low and the regression was strongly influenced the 2 large polluted estuaries, Gironde and Seine. This low correlation was not surprising for several reasons:

- The residual variability of the metrics not explained by the models was important, thus the related multimetric estimate of ecological status is associated with uncertainty.

- Contamination data for the sampled sites were chosen as descriptors of the anthropogenic pressures as they were available everywhere, directly correlated to the level of human pressure and appeared as good proxies for it. However, other human disturbances (habitat loss, anoxia, etc.; Peterson, 2003) are not taken into account with such proxy and the single effect of contamination did not quantify the whole anthropogenic pressure. To assess the 
Author-produced version of the article published in Marine Pollution Bulletin, 2010, vol. 60, n 6 , p. 908 - 918 The original publication is available at http://www.sciencedirect.com/

doi : 10.1016/j.marpolbul.2010.01.001

impact of anthropogenic disturbances on ecological status of estuaries, one of the main challenges is to determine relevant descriptors of these disturbances. While such a measure does not exist, the strength and accuracy of the link between index of ecological status and anthropogenic pressure can not be estimated and discrepancies in scoring pressure relations are difficult to analyse. Nevertheless, the proposed methodology allowed to build a fish index able to detect the impacts of the human activities on fishes and to evaluate the quality status of the fish communities in transitional waters.

To our knowledge, it is the first time that different scores are attributed according to the season and the salinity class in an estuarine fish-based index. These scores were added and the method employed to combine the metrics consisted in simple averaging. Systems to weight metrics exist (e.g. Kestemont et al., 2000; Aubry and Elliott, 2006) but the choice of nonweighing the metrics is the most commonly adopted and appears quite legitimate as the diagnostic supplied by the different metrics appeared of the same interest and not redundant. The present selection of non-redundant metrics reduces their number in the final index and validate this scoring approach. Another method consists in organizing the fish metrics according to the best balance between type I (falsely declaring the status of a site as disturbed while it is not) and type II (falsely declaring a disturbed site as undisturbed) error and stopping the addition of supplementary metrics in the index when the AUC criterion (Area Under the error Curve) is the lowest (Breine et al., 2007). Such method appeared very interesting to limit misclassification errors but the low number of selected metrics in this work prevents from using such complex selection approach.

Indeed, the number of selected metrics in this study seemed low compared with other multimetric fish indices and future works to consider additional metrics will be helpful to improve the assessment of ecological status in estuaries. Further alternatives can be used to 
Author-produced version of the article published in Marine Pollution Bulletin, 2010, vol. 60, n 6, p. 908 - 918

The original publication is available at http://www.sciencedirect.com/

doi : 10.1016/j.marpolbul.2010.01.001

538 index.

\section{Acknowledgments}

541 This study was partly financed by the French national scientific program Liteau II, directed by

542 the French Ministry of Ecology, Energy, Sustainable Development and Sea. We would like to

543 thank all the partners involved in the collect of survey data used in this study, notably Rachid

544 Amara (Université du littoral Cote d'Opale, France). We also thank the French Water

545 Agencies and Didier Pont (Cemagref, France) for his collaboration. The authors wish to thank

546 the anonymous reviewer for providing useful comments on the paper.

\section{$548 \quad$ References}


Author-produced version of the article published in Marine Pollution Bulletin, 2010, vol. 60, n 6, p. 908 - 918 The original publication is available at http://www.sciencedirect.com/

doi : 10.1016/j.marpolbul.2010.01.001

550 Anonymous, 2000. Establishing a framework for Community action in the field of water

551 policy. Directive 2000/60/EC of the European Parliament and of the Council of 23 October

552 2000. Official Journal of European Community L327, 1-72.

553 Araùjo, F.G., Bailey, R.G., Williams, W.P., 1998. Seasonal and between-year variations of

554 fish populations in the middle Thames estuary: 1980-1989. Fisheries Management and

555 Ecology 5, 1-21.

556 Aubry, A., Elliott, M., 2006. The use of environmental integrative indicators to assess seabed

557 disturbance in estuaries and coasts: Application to the Humber Estuary, UK. Marine Pollution

558 Bulletin 53, 175-185

559 Beliaeff, B., O'Connor, T.P., Claisse, D., 1998. Comparison of chemical concentrations in

560 mussels and oysters from the United States and France. Environmental Monitoring and

$561 \quad$ Assessment 49, 87-95.

562 Blaber, S.J.M., Cyrus, D.P., Albaret, J.J., Ching, C.V., Day, J.W., Elliott, M., Fonseca, M.S.,

563 Hoss, D.E., Orensanz, J., Potter, I.C., Silvert, W., 2000. Effects of fishing on the structure and

564 functioning of estuarine and nearshore ecosystems. ICES Journal of Marine Science 57, 590-

565602.

566 Borja, Á., Franco, J., Valencia, V., Bald, J., Muxika, I., Belzunce, M.J., Solaun, O., 2004.

567 Implementation of the European water framework directive from the Basque country

568 (northern Spain): a methodological approach. Marine Pollution Bulletin 48, 209-218.

569 Borja, A., Galparsoro, I., Solaun, O., Muxika, I., Tello, E.M., Uriarte, A., Valencia, V., 2006.

570 The European Water Framework Directive and the DPSIR, a methodological approach to

571 assess the risk of failing to achieve good ecological status. Estuarine, Coastal and Shelf

572 Science 66, 84-96. 
Author-produced version of the article published in Marine Pollution Bulletin, 2010, vol. 60, $n^{\circ} 6$, p. 908 - 918 The original publication is available at http://www.sciencedirect.com/

doi : 10.1016/j.marpolbul.2010.01.001

573 Breine, J.J., Maes, J., Quataert, P., Van den Bergh, E., Simoens, I., Van Thuyne, G., Belpaire,

C., 2007. A fish-based assessment tool for the ecological quality of the brackish Schelde estuary in Flanders (Belgium). Hydrobiologia 575, 141.

Breine, J.J., Simoens, I., Goethals, P., Quataert, P., Ercken, D., Van Liefferinghe, C.,

Belpaire, C., 2004. A fish-based index of biotic integrity for upstream brooks in Flanders

578 (Belgium). Hydrobiologia 522, 133-148.

579 Cabral, H.N., Costa, M.J., Salgado, J.P., 2001. Does the Tagus estuary fish community reflect environmental changes? Climate Research 18, 119-126.

Claridge, P.N., Potter, I.C., Hardisty, M.W., 1986. Seasonal changes in movements, abundance, size composition and diversity of the fish fauna of the Severn estuary. Journal of

583 the Marine Biological Association of the United Kingdom 66, 229-258.

584 Cloern, J.E., 2001. Our evolving conceptual model of the coastal eutrophication problem.

585 Marine Ecology Progress Series 210, 223-253.

586 Coates, S., Waugh, A., Anwar, A., Robson, M., 2007. Efficacy of a multi-metric fish index as 587 an analysis tool for the transitional fish component of the Water Framework Directive. Marine 588 Pollution Bulletin 55, 225-240.

589 Coates, S.A., Colclough, S.R., Robson, M.A., Harrison, T.D., 2004. Development of an 590 estuarine classification scheme for the Water Framework Directive. Phases 1 \& 2 -

591 Transitional fish component. R\&D Technical Report E1-131/TR. Bristol: Environment

592 Agency, $55 \mathrm{pp}$.

593 Cooper, J.A.G., Ramm, A.E.L., Harrison, T.D., 1994. The estuarine health index: A new 594 approach to scientific information transfer. Ocean and Coastal Management 25, 103-141.

595 Courrat, A., Lobry, J., Nicolas, D., Laffargue, P., Amara, R., Lepage, M., Girardin, M., Le 596 Pape, O., 2009. Anthropogenic disturbance on nursery function of estuarine areas for marine 597 species. Estuarine, Coastal and Shelf Science 81, 179-190. 
Author-produced version of the article published in Marine Pollution Bulletin, 2010, vol. 60, n 6, p. 908 - 918 The original publication is available at http://www.sciencedirect.com/

doi : 10.1016/j.marpolbul.2010.01.001

598 Dauvin, J.C., 2008. The main characteristics, problems, and prospects for Western European coastal seas. Marine Pollution Bulletin 57, 22-40.

600 Dauvin, J.C., Ruellet, T., 2009. The estuarine quality paradox: Is it possible to define an

601 ecological quality status for specific modified and naturally stressed estuarine ecosystems?

602 Marine Pollution Bulletin 59, 38-47.

603 Deegan, L.A., Finn, J.T., Ayvazian, S.G., Ryder-Kieffer, C.A., Buonaccorsi, J., 1997.

604 Development and validation of an estuarine biotic integrity index. Estuaries 20, 601-617.

605 Elliott, M., Dewailly, F., 1995. The structure and components of European estuarine fish

606 assemblages. Netherlands Journal of Aquatic Ecology 29, 397-417.

607 Elliott, M., Griffiths, A.H., Taylor, C.J.L., 1988. The role of fish studies in estuarine pollution 608 assessment. Journal of Fish Biology 33 (SUPPL. 1), 51-61.

609 Elliott, M., Hemingway, K.L., 2002. Fishes in Estuaries. Blackwell Science, London, 636 pp.

610 Elliott, M., O'Reilly, M.G., Taylor, C.J.L., 1990. The Forth estuary: a nursery and

611 overwintering area for North Sea fishes. Hydrobiologia 195, 89-103.

612 Elliott, M., Quintino, V., 2007. The Estuarine Quality Paradox, Environmental Homeostasis 613 and the difficulty of detecting anthropogenic stress in naturally stressed areas. Marine

614 Pollution Bulletin 54, 640-645.

615 Elliott, M., Whitfield, A.K., Potter, I.C., Blaber, S.J.M., Cyrus, D.P., Nordlie, F.G., Harrison, 616 T.D., 2007. The guild approach to categorizing estuarine fish assemblages: A global review.

617 Fish and Fisheries 8, 241-268.

618 Fausch, K.D., Lyons, J., Karr, J.R., Angermeier, P.L., 1990. Fish communities as indicators of 619 environmental degradation. American Fisheries Society Symposium 8, 123-144.

620 Franco, A., Elliott, M., Franzoi, P., Torricelli, P., 2008a. Life strategies of fishes in European 621 estuaries: The functional guild approach. Marine Ecology Progress Series 354, 219-228. 
Author-produced version of the article published in Marine Pollution Bulletin, 2010, vol. 60, $\mathrm{n}^{\circ} 6, \mathrm{p} .908$ - 918 The original publication is available at http://www.sciencedirect.com/

doi : 10.1016/j.marpolbul.2010.01.001

622 Franco, A., Franzoi, P., Malavasi, S., Riccato, F., Torricelli, P., 2006. Fish assemblages in

623 different shallow water habitats of the Venice Lagoon. Hydrobiologia 555, 159-174.

624 Franco, A., Franzoi, P., Torricelli, P., 2008b. Structure and functioning of Mediterranean

625 lagoon fish assemblages: A key for the identification of water body types. Estuarine, Coastal

626 and Shelf Science 79, 549-558.

627 Gibson, R.N., 1994. Impact of habitat quality and quantity on the recruitment of juvenile

628 flatfishes. Netherlands Journal of Sea Research 32, 191-206.

629 Gilliers, C., Le Pape, O., Désaunay, Y., Morin, J., Guérault, D., Amara, R., 2006. Are growth

630 and density quantitative indicators of essential fish habitat quality? An application to the

631 common sole Solea solea nursery grounds. Estuarine, Coastal and Shelf Science 69, 96-106.

632 Harrison, T.D., Whitfield, A.K., 2004. A multi-metric fish index to assess the environmental

633 condition of estuaries. Journal of Fish Biology 65, 683-710.

634 Hering, D., Feld, C.K., Moog, O., Ofenböck, T., 2006. Cook book for the development of a

635 Multimetric Index for biological condition of aquatic ecosystems: Experiences from the

636 European AQEM and STAR projects and related initiatives. Hydrobiologia 566, 311-324.

637 Hughes, R.M., Gakstatter, J.H., Shirazi, M.A., Omernik, J.M., 1982. An approach for

638 determining biological integrity in flowing waters. In: Brann, T.B., House, L.O.IV, Lund,

639 H.G. (Eds), Place Resource Inventories: Principles and Practices. Society of American

640 Foresters, Bethesda, MD, pp. 877-888.

641 Hughes, R.M., Kaufmann, P.R., Herlihy, A.T., Kincaid, T.M., Reynolds, L., Larsen, D.P.,

642 1998. A process for developing and evaluating indices of fish assemblage integrity. Canadian

643 Journal of Fisheries and Aquatic Sciences 55, 1618-1631.

644 Karr, J.R., 1981. Assessment of biotic integrity using fish communities. Fisheries 6, 21-27. 
Author-produced version of the article published in Marine Pollution Bulletin, 2010, vol. 60, n 6, p. 908 - 918 The original publication is available at http://www.sciencedirect.com/

doi : 10.1016/j.marpolbul.2010.01.001

645 Karr, J.R., Fausch, K.D., Angermeier, P.L., Yant, P.R., Schlosser, J.J., 1986. Assessing

646 biological integrity in running waters: A method and its rationale. Special Publication 5,

647 Illinois Natural History Survey.

648 Kestemont, P., Didier, J., Depiereux, E., Micha, J.C., 2000. Selecting ichthyological metrics

649 to assess river basin ecological quality. Archiv Für Hydrobiologie 121, 321-348.

650 Koutrakis, E.T., Tsikliras, A.C., Sinis, A.I., 2005. Temporal variability of the ichthyofauna in

651 a Northern Aegean coastal lagoon (Greece). Influence of environmental factors.

652 Hydrobiologia 543, 245-257.

653 Krebs, C.J., 1999. Ecological Methodology. Addison-Wesley Educational Publishers,

654 California, USA, 654 pp.

655 Le Pape, O., Chauvet, F., Mahévas, S., Lazure, P., Guérault, D., Désaunay, Y., 2003.

656 Quantitative description of habitat suitability for the juvenile common sole (Solea solea, L.) in 657 the Bay of Biscay (France) and the contribution of different habitats to the adult population.

658 Journal of Sea Research 50, 139-149.

659 Le Pape, O., Gilliers, C., Riou, P., Morin, J., Amara, R., Désaunay, Y., 2007. Convergent

660 signs of degradation in both the capacity and the quality of an essential fish habitat: State of

661 the Seine estuary (France) flatfish nurseries. Hydrobiologia 588, 225-229.

662 Lepage, M., Girardin, M., 2006. Inventaire Poisson dans les eaux de transition. Protocole

663 d'échantillonnage de la façade Atlantique et Manche. Report for the French Ministry in

664 charge of the Environment, Cemagref, Bordeaux, France, 32 pp.

665 Levrel, H., 2007. Selecting indicators for the management of biodiversity, Cahier de l'IFB,

666 Institut Français de la Biodiversité, Paris, France, 93 pp.

667 Lobry, J., Lepage, M., Rochard, E., 2006. From seasonal patterns to a reference situation in an

668 estuarine environment: Example of the small fish and shrimp fauna of the Gironde estuary

669 (SW France). Estuarine, Coastal and Shelf Science 70, 239-250. 
Author-produced version of the article published in Marine Pollution Bulletin, 2010, vol. 60, n 6, p. 908 - 918

The original publication is available at http://www.sciencedirect.com/

doi : 10.1016/j.marpolbul.2010.01.001

Lobry, J., Mourand, L., Rochard, E., Elie, P., 2003. Structure of the Gironde estuarine fish assemblages: a European estuaries comparison perspective. Aquatic Living Resources 16, 4758.

Maes, J., Stevens, M., Ollevier, F., 2005. The composition and community structure of the ichthyofauna of the upper Scheldt estuary: Synthesis of a 10-year data collection (1991-2001). Journal of Applied Ichthyology 21, 86-93.

Marshall, S., Elliott, M., 1998. Environmental influences on the fish assemblage of the Humber estuary, U.K. Estuarine, Coastal and Shelf Science 46, 175-184.

McDowall, R.M., Taylor, M.J., 2000. Environmental indicators of habitat quality in a migratory freshwater fish fauna. Environmental Management 25, 357-374.

McLusky, D.S., 1981. The Estuarine Ecosystem, Blackie, Glasgow, 150 pp.

Monaco, M.E., Lowery, T.A., Emmett, R.L., 1992. Assemblages of US west coast estuaries based on the distribution of fishes. Journal of Biogeography 19, 251-267.

Mouillot, D., Spatharis, S., Reizopoulou, S., Laugier, T., Sabetta, L., Basset, A., Chi, T.D., 2006. Alternatives to taxonomic-based approaches to assess changes in transitional water communities. Aquatic Conservation-Marine and Freshwater Ecosystems 16, 469-482.

Nicolas, D., Le Loc'h, F., Désaunay, Y., Hamon, D., Blanchet, A., Le Pape, O., 2007. Relationships between benthic macrofauna and habitat suitability for juvenile common sole (Solea solea, L.) in the Vilaine estuary (Bay of Biscay, France) nursery ground. Estuarine, Coastal and Shelf Science 73, 639-650.

Nicolas, D., Lobry, J., Lepage, M., Sautour, B., Le Pape, O., Cabral, H., Uriarte, A., Boët, P., In press. Fish under influence: a macroecological analysis of relations between fish species richness and environmental gradients among European tidal estuaries. Estuarine, Coastal and Shelf Science (2009), doi:10.1016/j.ecss.2009.11.006. 
Author-produced version of the article published in Marine Pollution Bulletin, 2010, vol. 60, n 6, p. 908 - 918 The original publication is available at http://www.sciencedirect.com/

doi : 10.1016/j.marpolbul.2010.01.001

694 Oberdorff, T., Hughes, R.M., 1992. Modification of an Index of Biotic Integrity based on fish assemblages to characterize rivers of the Seine Basin, France. Hydrobiologia 228, 117-130.

696 Oberdorff, T., Pont, D., Hugueny, B., Chessel, D., 2001. A probabilistic model characterizing

697 fish assemblages of French rivers: A framework for environmental assessment. Freshwater

698 Biology 46, 399-415.

699 Oberdorff, T., Pont, D., Hugueny, B., Porcher, J.P., 2002. Development and validation of a

700 fish-based index for the assessment of 'river health' in France. Freshwater Biology 47, 1720-

$701 \quad 1734$.

702 Oberdorff, T., Porcher, J.P., 1994. An index of biotic integrity to assess biological impacts of

703 salmonid farm effluents on receiving waters. Aquaculture 119, 219-235.

704 Peterson, M.S., 2003. A conceptual view of environment-habitat-production linkages in tidal 705 river estuaries. Reviews in Fisheries Science 11, 291-313.

706 Pomfret, J.R., Elliott, M., O'Reilly, M.G., Phillips, S., 1991. Spatial and temporal patterns in

707 the fish communities in two UK North Sea estuaries. In: Elliott, M., Ducrotoy, J.P. (Eds),

708 Estuaries and coasts : spatial and temporal intercomparisons. Olsen and Olsen, Fredensborg,

709 Denmark, pp. 277-284.

710 Pont, D., Hugueny, B., Beier, U., Goffaux, D., Melcher, A., Noble, R., Rogers, C., Roset, N.,

711 Schmutz, S., 2006. Assessing river biotic condition at a continental scale: A European

712 approach using functional metrics and fish assemblages. Journal of Applied Ecology 43, 70-

71380.

714 Quataert, P., Breine, J., Simoens, I., 2007. Evaluation of the European Fish Index: False-

715 positive and false-negative error rate to detect disturbance and consistency with alternative

716 fish indices. Fisheries Management and Ecology 14, 465-472. 
Author-produced version of the article published in Marine Pollution Bulletin, 2010, vol. 60, n 6, p. 908 - 918 The original publication is available at http://www.sciencedirect.com/

doi : 10.1016/j.marpolbul.2010.01.001

717 R Development Core Team, 2005. R: A language and environment for statistical computing.

718 R Foundation for Statistical Computing, Vienna, Austria, ISBN 3-900051-07-0. URL:

719 http://www.R-project.org.

720 Ramm, A.E., 1988. The community degradation index: A new method for assessing the

721 deterioration of aquatic habitats. Water Research 22, 293-301.

722 Root, R.B., 1967. The niche exploitation pattern of the blue-gray gnatcatcher. Ecological

723 Monographs 37, 317-350.

724 Roset, N., Grenouillet, G., Goffaux, D., Pont, D., Kestemont, P., 2007. A review of existing

725 fish assemblage indicators and methodologies. Fisheries Management and Ecology 14, 393-

726405.

727 Roth, N., Southerland, M., Chaillou, J., Klauda, R., Kazyak, P., Stranko, S., Weisberg, S.,

728 Hall Jr, L., Morgan Ii, R., 1998. Maryland biological stream survey: Development of a fish

729 index of biotic integrity. Environmental Monitoring and Assessment 51, 89-106.

730 Roy, P.S., Williams, R.J., Jones, A.R., Yassini, I., Gibbs, P.J., Coates, B., West, R.J., Scanes,

731 P.R., Hudson, J.P., Nichol, S., 2001. Structure and function of south-east Australian estuaries.

732 Estuarine, Coastal and Shelf Science 53, 351-384.

733 Stefansson, G., 1996. Analysis of groundfish survey abundance data: Combining the GLM

734 and delta approaches. ICES Journal of Marine Science 53, 577-588.

735 Stoddard, J.L., Herlihy, A.T., Peck, D.V., Hughes, R.M., Whittier, T.R., Tarquinio, E., 2008.

736 A process for creating multimetric indices for large-scale aquatic surveys. Journal of the

737 North American Benthological Society 27, 878-891.

738 Thiel, R., Cabral, H., Costa, M.J., 2003. Composition, temporal changes and ecological guild

739 classification of the ichthyofaunas of large European estuaries - A comparison between the

740 Tagus (Portugal) and the Elbe (Germany). Journal of Applied Ichthyology 19, 330-342. 
Author-produced version of the article published in Marine Pollution Bulletin, 2010, vol. 60, n 6, p. 908 - 918 The original publication is available at http://www.sciencedirect.com/

doi : 10.1016/j.marpolbul.2010.01.001

741 Thiel, R., Potter, I.C., 2001. The ichthyofaunal composition of the Elbe Estuary: An analysis

742 in space and time. Marine Biology 138, 603-616.

743 Thiel, R., Sepulveda, A., Kafemann, R., Nellen, W., 1995. Environmental-Factors as Forces

744 Structuring the Fish Community of the Elbe Estuary. Journal of Fish Biology 46, 47-69.

745 Uriarte, A., Borja, A., 2009. Assessing fish quality status in transitional waters, within the

746 European Water Framework Directive: Setting boundary classes and responding to

747 anthropogenic pressures. Estuarine, Coastal and Shelf Science 82, 214-224.

748 USEPA, 2000. Estuarine and coastal marine waters: bioassessment and biocriteria technical

749 guidance. US Environmental Protection Agency Report.

750 Whitfield, A.K., Elliott, A., 2002. Fishes as indicators of environmental and ecological

751 changes within estuaries: a review of progress and some suggestions for the future. Journal of

752 Fish Biology 61, 229-250.

753

754

755

756 
Author-produced version of the article published in Marine Pollution Bulletin, 2010, vol. 60, n 6, p. 908 - 918

The original publication is available at http://www.sciencedirect.com/

doi : 10.1016/j.marpolbul.2010.01.001

\section{$757 \quad$ Figure captions}

758 Fig. 1. Location of the 13 French estuaries considered in the present study.

759 Fig. 2. General methodology for testing the impacts of anthropogenic disturbances on

760 transitional water functions from fish metrics and building a multimetric fish index (adapted

761 from Courrat et al. (2009)).

762 Fig. 3. Indices of heavy metals, organic and overall contaminations for the 13 studied

763 estuaries classified according to an ascending level of overall contamination. Arrows indicate

764 the levels of pressure used for prediction from fish metrics' models.

765 Fig. 4. Test of discriminance of the effect of anthropogenic pressures on predicted values of

766 fish metrics, with associated thresholds (horizontal lines) and scores. Example for a metric

767 expressed in log-density. a: Illustration of non overlapping quantiles. b: Methodology adopted

768 for the scoring when quantiles slightly overlapped. c: strong overlapping leading to reject the

769 metric. Circles represent the metric values calculated for high (black). intermediate (grey) and

770 low (white) values of the anthropogenic pressure index (fitted values from the models).

771 Triangles correspond to 10 and $90 \%$ quantiles.

772 Fig. 5. Values of the multimetric fish index calculated for each of the 13 Atlantic and English

773 Channel estuaries.

774 Fig. 6. Relationship between the multimetric fish index and the index of contamination for the

77513 studied estuaries.

776 
Author-produced version of the article published in Marine Pollution Bulletin, 2010, vol. 60, $\mathrm{n}^{\circ} 6, \mathrm{p} .908$ - 918 The original publication is available at http://www.sciencedirect.com/

doi : 10.1016/j.marpolbul.2010.01.001

Table 1.

Number of trawl hauls performed in each estuary according to seasons and salinity gradient.

\begin{tabular}{lllllllll} 
& \multicolumn{7}{l}{ Spring } & \multicolumn{7}{c}{ Autumn } \\
\cline { 2 - 8 } & oligohaline & mesohaline & polyhaline & $\Sigma$ & oligohaline & mesohaline & polyhaline & $\Sigma$ \\
\hline Adour & 10 & 6 & 3 & 19 & 16 & 5 & 8 & 29 \\
Authie & 3 & & 12 & 15 & 4 & 1 & 10 & 15 \\
Bidassoa & & 3 & 9 & 12 & & 1 & 21 & 22 \\
Canche & 3 & 3 & 9 & 15 & 3 & 1 & 13 & 17 \\
Charente & 4 & 5 & 8 & 17 & 11 & & 11 & 22 \\
Gironde & 14 & 41 & 23 & 78 & 2 & 37 & 34 & 73 \\
Loire & 7 & 10 & 11 & 28 & 22 & 10 & 13 & 45 \\
Mont Saint & & & & & & & & \\
Michel Bay & 6 & 22 & 28 & 8 & & 25 & 33 \\
Orne & 7 & 2 & 8 & 17 & 7 & 1 & 10 & 18 \\
Seine & 11 & 2 & 24 & 37 & 10 & 6 & 27 & 43 \\
Seudre & & & 17 & 17 & & & 23 & 23 \\
Somme & 2 & 6 & 18 & 26 & 1 & 4 & 22 & 27 \\
Veys Bay & 2 & 2 & 25 & 29 & & 3 & 26 & 29 \\
\hline
\end{tabular}


Author-produced version of the article published in Marine Pollution Bulletin, 2010, vol. 60, $\mathrm{n}^{\circ} 6, \mathrm{p} .908$ - 918 The original publication is available at http://www.sciencedirect.com/

doi : 10.1016/j.marpolbul.2010.01.001

Table 2.

List of the ecological, trophic and vertical distribution guilds (adapted from Elliott and Dewailly (1995)).

\begin{tabular}{|c|c|c|}
\hline Criteria & Guilds & Definition \\
\hline \multirow{6}{*}{ Ecology } & $\begin{array}{l}\text { DIA: Diadromous migrant } \\
\text { species }\end{array}$ & $\begin{array}{l}\text { Species that use transitional waters to pass } \\
\text { between salt and fresh waters for spawning and } \\
\text { feeding }\end{array}$ \\
\hline & $\begin{array}{l}\text { ER: Estuarine resident } \\
\text { species }\end{array}$ & $\begin{array}{l}\text { Species that spend their entire life in the } \\
\text { transitional waters }\end{array}$ \\
\hline & FW: Freshwater species & $\begin{array}{l}\text { Freshwater species that occasionally come into } \\
\text { transitional waters but not dependant of these } \\
\text { systems }\end{array}$ \\
\hline & $\begin{array}{l}\text { MA: Marine adventitious } \\
\text { visitors }\end{array}$ & $\begin{array}{l}\text { Species that appear irregularly in the } \\
\text { transitional waters but have no apparent } \\
\text { transitional water requirements }\end{array}$ \\
\hline & $\begin{array}{l}\text { MJ: Marine juvenile migrant } \\
\text { species }\end{array}$ & $\begin{array}{l}\text { Species that use the transitional waters } \\
\text { primarily as a nursery ground }\end{array}$ \\
\hline & $\begin{array}{l}\text { MS: Marine seasonal } \\
\text { migrants species }\end{array}$ & $\begin{array}{l}\text { Species that have regular seasonal visits to the } \\
\text { transitional waters, usually as adults }\end{array}$ \\
\hline \multirow{6}{*}{ Trophic } & V: Herbivorous & $\begin{array}{l}\text { Species that feed by grazing on macroalgae or } \\
\text { other macrophytes }\end{array}$ \\
\hline & Z: Zooplankton predators & $\begin{array}{l}\text { Species that feed exclusively or mainly on } \\
\text { zooplankton }\end{array}$ \\
\hline & $\begin{array}{l}\text { IB: Benthic invertebrate } \\
\text { predators }\end{array}$ & $\begin{array}{l}\text { Species that feed exclusively or mainly on } \\
\text { benthic invertebrate }\end{array}$ \\
\hline & IS: Suprabenthic invertebrate & $\begin{array}{l}\text { Species that feed exclusively or mainly on } \\
\text { suprabenthic invertebrate }\end{array}$ \\
\hline & F: Fish feeders & Species that feed exclusively or mainly on fish \\
\hline & O: Omnivorous & $\begin{array}{l}\text { Species that feed on all the available resources } \\
\text { that can be consumed }\end{array}$ \\
\hline \multirow{3}{*}{$\begin{array}{l}\text { Vertical } \\
\text { distribution }\end{array}$} & P: Pelagic species & Species that live in the main water column \\
\hline & D: Demersal fishes & $\begin{array}{l}\text { Species that live in the water layer just above } \\
\text { the bottom }\end{array}$ \\
\hline & B: Benthic species & Species that live on or in the substratum \\
\hline
\end{tabular}


Author-produced version of the article published in Marine Pollution Bulletin, 2010, vol. 60, $\mathrm{n}^{\circ} 6, \mathrm{p} .908$ - 918

The original publication is available at http://www.sciencedirect.com/

doi : 10.1016/j.marpolbul.2010.01.001

Table 3.

Candidate metrics and their expected response with increasing degradations defined according

to expert judgment. (-) Decreasing.

\begin{tabular}{lll}
\hline Candidate metrics & Abbreviations & $\begin{array}{l}\text { Expected response } \\
\text { face to increasing } \\
\text { degradation }\end{array}$ \\
\hline $\begin{array}{l}\text { Diversity and abundance descriptors } \\
\text { 1. Species richness }\end{array}$ & SR \\
2. Total density & TD & $(-)$ \\
Functionality descriptors & & \\
Ecological guilds & & $(-)$ \\
3. Number of diadromous migrant species & NSDIA & $(-)$ \\
4. Density of diadromous migrant species & DDIA & $(-)$ \\
5. Number of freshwater species & NSFW & $(-)$ \\
6. Density of freshwater species & DFW & $(-)$ \\
7. Number of marine juvenile migrant species & NSMJ & $(-)$ \\
8. Density of marine juvenile migrant species & DMJ & $(-)$ \\
9. Number of marine seasonal migrant & NSMS & $(-)$ \\
10. Density of marine seasonal migrant & DMS & \\
& & $(-)$ \\
Trophic guilds & & $(-)$ \\
11. Number of benthic invertebrate feeder species & NSIB & $(-)$ \\
12. Density of benthic invertebrate feeder species & DIB & $(-)$ \\
13. Number of fish feeder species & NSF & \\
14. Density of fish feeder species & DF & $(-)$ \\
Vertical distribution guilds & & $(-)$ \\
15. Number of benthic species & NSB & \\
16. Density of benthic species & DB & \\
\hline
\end{tabular}


Author-produced version of the article published in Marine Pollution Bulletin, 2010, vol. 60, $n^{\circ}$ 6, p. 908 - 918 The original publication is available at http://www.sciencedirect.com/ doi : 10.1016/j.marpolbul.2010.01.001

Table 4.

Summary of the models used for each candidate metrics. *, **,*** the factors or pressure effects are significant at respectively the $0.05,0.01$ and 0.001 levels. The metric significantly decreased (-), increased (+) or showed no significant trend (NS) with increasing pressure. (4.6): the percentage of the variability explained. Resid. df: Residual degree of freedom. Comp:: Comparison between expert judgements and models: $=:$ the pressure effect is the same; $\neq$ : is different. Corr.: Pairs of metrics (a1-a2) strongly correlated. Disc. thres.: the calculated thresholds were discriminant $(\mathrm{Y})$ or not $(\mathrm{N})$.

\begin{tabular}{|c|c|c|c|c|c|c|c|c|c|c|c|}
\hline \multirow{2}{*}{$\begin{array}{l}\text { Candidate } \\
\text { metrics }\end{array}$} & \multirow{2}{*}{ Model } & \multicolumn{4}{|c|}{ Protocol and environmental descriptors } & \multirow{2}{*}{$\begin{array}{l}\text { Pressure } \\
\text { effect }\end{array}$} & \multirow{2}{*}{\multicolumn{2}{|c|}{$\begin{array}{l}\text { Resid. Comp. } \\
\text { df }\end{array}$}} & \multirow{2}{*}{ Corr. } & \multirow{2}{*}{$\begin{array}{l}\text { Disc. } \\
\text { thres. }\end{array}$} & \multirow{2}{*}{$\begin{array}{l}\text { Selected } \\
\text { metrics }\end{array}$} \\
\hline & & Season & Salinity & Surface & Ecoregion & & & & & & \\
\hline \multicolumn{12}{|c|}{ Diversity and abundance descriptors } \\
\hline SR & Poisson & & $* * *(4.6)$ & $* * *(12.5)$ & $* * *(5.6)$ & $-* * *(2.5)$ & 728 & $=$ & & $\mathrm{N}$ & \\
\hline \multirow[t]{2}{*}{ TD } & log-normal & & & $* * *(9.0)$ & $* * *(9.3)$ & $-* * *(5.6)$ & 688 & $=$ & & $\mathrm{Y}$ & $X$ \\
\hline & Binomial & & & $* * *(3.9)$ & $* * *(4.9)$ & NS & 730 & & & $Y$ & $\lambda$ \\
\hline \multirow{2}{*}{\multicolumn{12}{|c|}{$\begin{array}{l}\text { Functionality descriptors } \\
\text { Ecological guilds }\end{array}$}} \\
\hline & & & & & & & & & & & \\
\hline NSDIA & Poisson & $* *(1.1)$ & $* * *(7.7)$ & $* * *(11.3)$ & $* * *(8.3)$ & $-* * *(2.7)$ & 727 & $=$ & & $\mathrm{N}$ & \\
\hline \multirow[t]{2}{*}{ DDIA } & log-normal & & $* * *(6.2)$ & $* * *(6.5)$ & $* * *(12.0)$ & $-* * *(9.8)$ & 375 & $=$ & & & \\
\hline & Binomial & $* * *(1.5)$ & $* * *(6.4)$ & $* * *(7.1)$ & $* * *(8.9)$ & NS & 727 & & & $Y$ & $X$ \\
\hline NSMJ & Poisson & & $* * *(13.9)$ & $* * *(5.0)$ & $* * *(8.2)$ & $-* * *(3.9)$ & 728 & $=$ & & $\mathrm{N}$ & \\
\hline \multirow[t]{2}{*}{ DMJ } & log-normal & $*(0.8)$ & & $* * *(6.3)$ & $* * *(4.2)$ & $-* * *(7.1)$ & 436 & $=$ & & $\mathrm{Y}$ & $\mathrm{X}$ \\
\hline & Binomial & & $* * *(9.6)$ & $* * *(1.5)$ & $* * *(5.3)$ & $-* * *(3.7)$ & 728 & & & $\mathbf{Y}$ & $\lambda$ \\
\hline NSMS & Poisson & & $* * *(10.2)$ & $* * *(5.6)$ & $* * *(2.7)$ & NS & 728 & & & & \\
\hline \multirow[t]{2}{*}{ DMS } & log-normal & $* * *(2.4)$ & $*(1.2)$ & $* * *(36.1)$ & & $+* * *(1.5)$ & 311 & $\neq$ & & & \\
\hline & Binomial & $* *(1)$ & $* * *(9.3)$ & $* * *(6.2)$ & $*(0.5)$ & NS & 727 & & & & \\
\hline \multicolumn{12}{|c|}{ Trophic guilds } \\
\hline NSIB & Poisson & & $*(0.9)$ & $* *(1.0)$ & $* * *(6.7)$ & $-* * *(2.1)$ & 728 & $=$ & a1 & & \\
\hline \multirow[t]{2}{*}{ DIB } & log-normal & & $* * *(2.0)$ & $* * *(12.4)$ & $* * *(6.7)$ & $-* * *(6.1)$ & 625 & $=$ & b1 & & \\
\hline & Binomial & $*(0.7)$ & & & $*(0.8)$ & NS & 730 & & & & \\
\hline \multicolumn{12}{|c|}{ Vertical distribution guilds } \\
\hline NSB & Poisson & & $* * *(5.3)$ & $* * *(2.4)$ & $* * *(4.3)$ & $-* * *(1.6)$ & 728 & $=$ & $\mathrm{a} 2$ & $\mathrm{~N}$ & \\
\hline DB & log-normal & & $* * *(2.2)$ & $* * *(12.1)$ & $* * *(6.7)$ & $-* * *(6.1)$ & 621 & $=$ & b2 & $\mathrm{Y}$ & $X$ \\
\hline & Binomial & & $*(1.3)$ & & $*(1.2)$ & NS & 729 & & & $\mathbf{Y}$ & $\lambda$ \\
\hline
\end{tabular}


Author-produced version of the article published in Marine Pollution Bulletin, 2010, vol. 60, $n^{\circ}$ 6, p. 908 - 918 The original publication is available at http://www.sciencedirect.com/ doi : 10.1016/j.marpolbul.2010.01.001

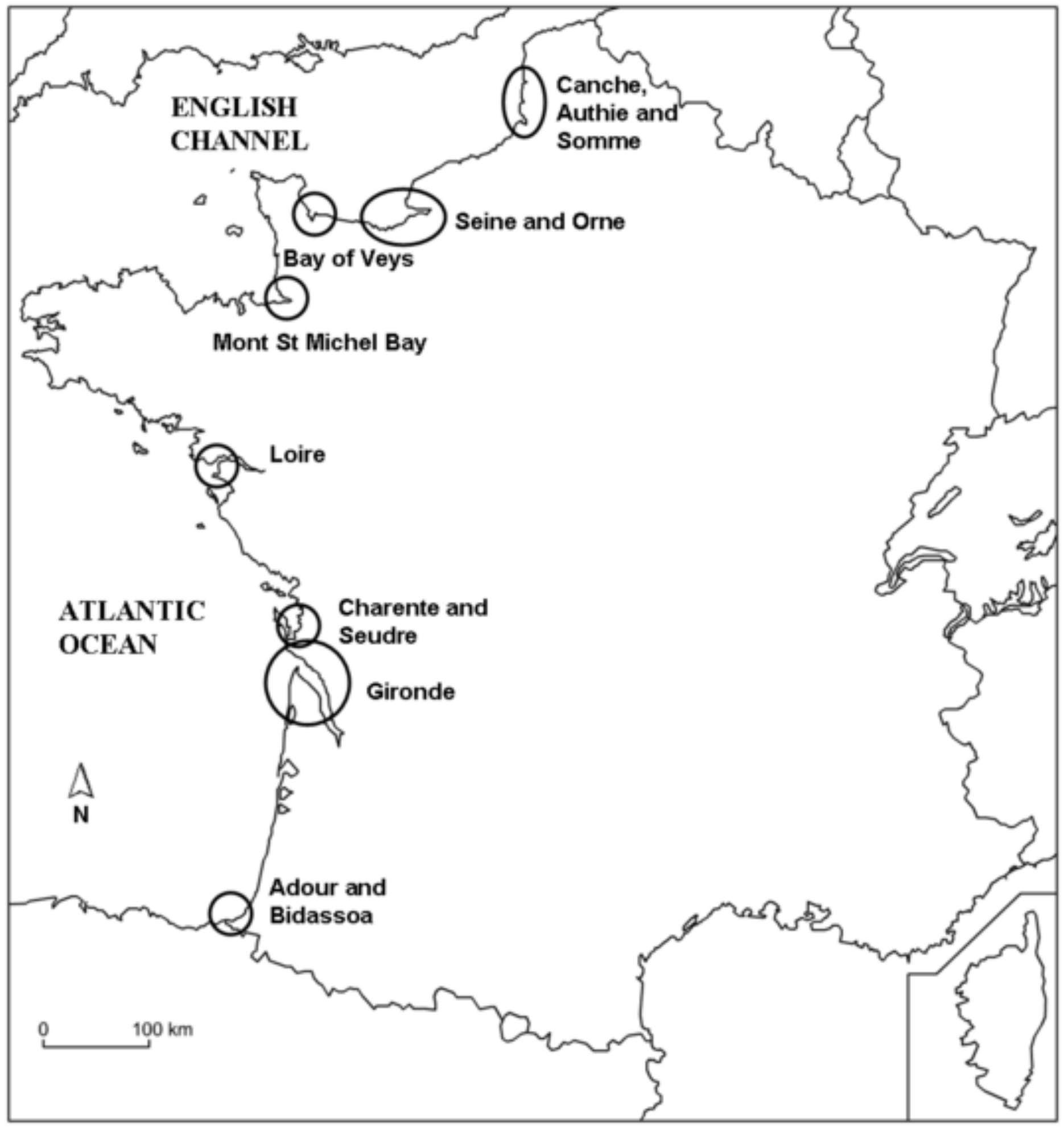


Author-produced version of the article published in Marine Pollution Bulletin, 2010, vol. 60, $n^{\circ}$ 6, p. 908 - 918

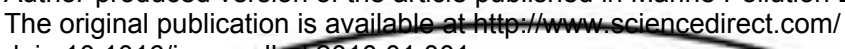
doi : 10.1016/j.marpetbut.2010.01.001
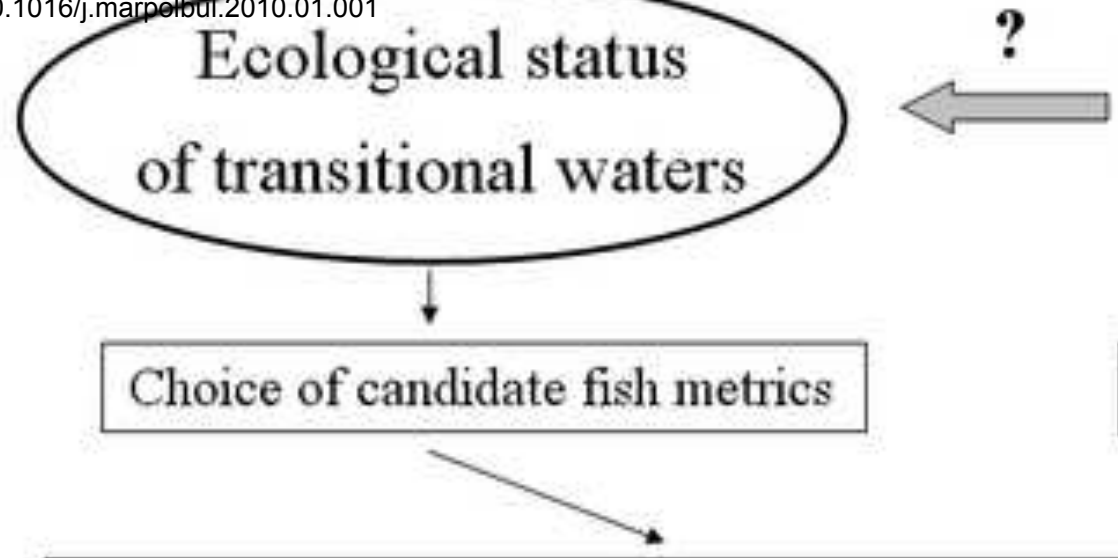

\section{Anthropogenic disturbances}

Modelling : Impact of anthropogenic disturbance proxies on fish metrics

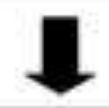

Selection of sensitive, non redundant metrics

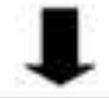

Proxy: descriptors of contaminations

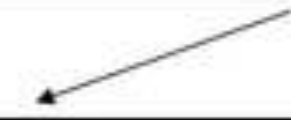

Thresholds calculation

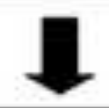

Selection of discriminant metrics

$I$

Scoring, combination of scores into a multimetric index

I

Validation from the comparison with anthropogenic disturbance 
Click here to download high resolution image

Author-produced version of the article published in Marine Pollution Bulletin, 2010, vol. 60, $n^{\circ}$ 6, p. 908 - 918 The original publication is available at http://www.sciencedirect.com/ doi : 10.1016/j.marpolbul.2010.01.001

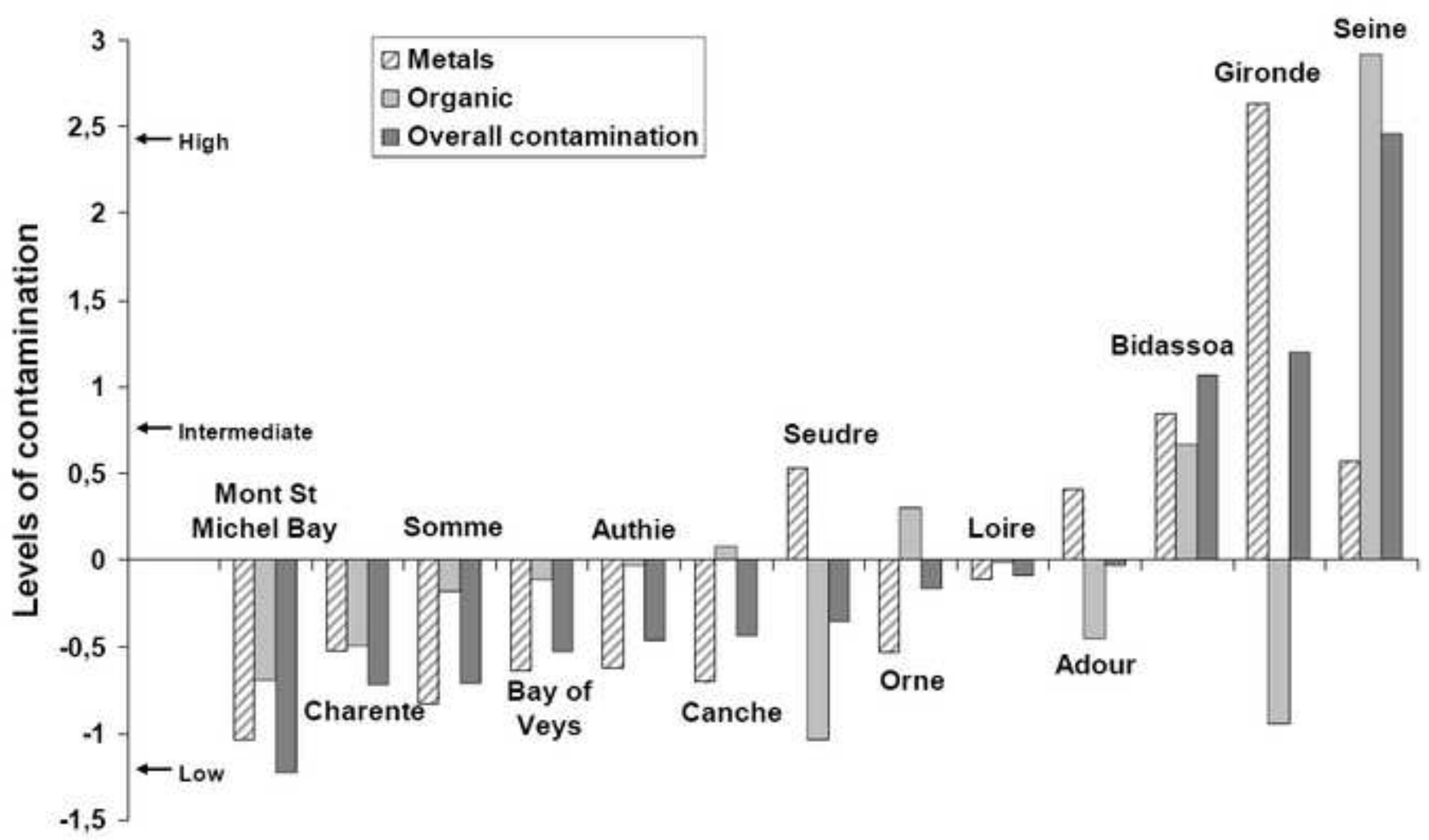


Author-produced version of the article published in Marine Pollution Bulletin, 2010, vol. 60, $n^{\circ}$ 6, p. 908 - 918 The original publication is available at http://www.sciencedirect.com/

doi : 10.1016/j.marpolbul.2010.01.001

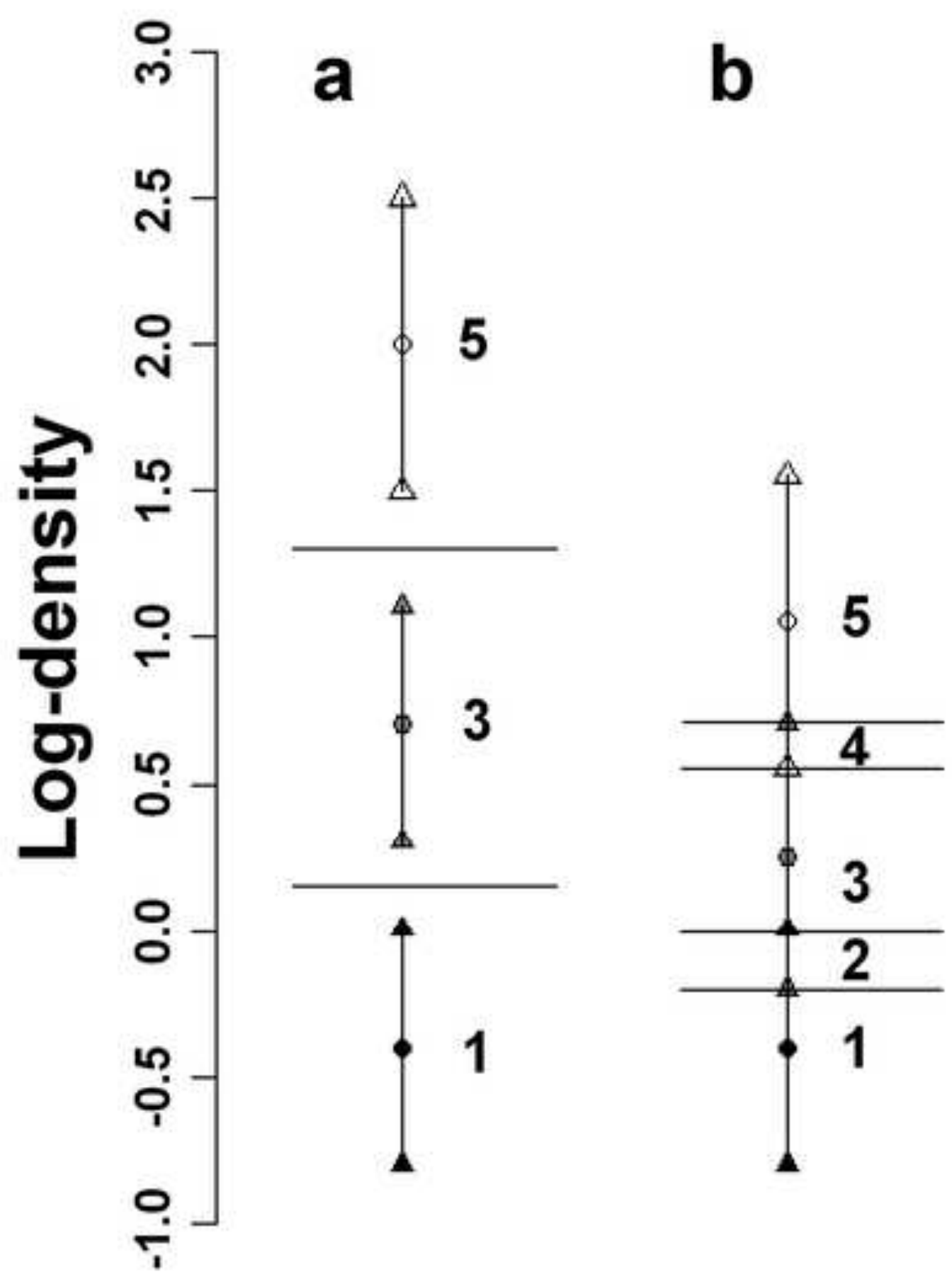




\section{Figure5}

Click here to download high resolution image

Author-produced version of the article published in Marine Pollution Bulletin, 2010, vol. 60, n 6, p. 908 - 918 The original publication is available at http://www.sciencedirect.com/ doi : 10.1016/j.marpolbul.2010.01.001

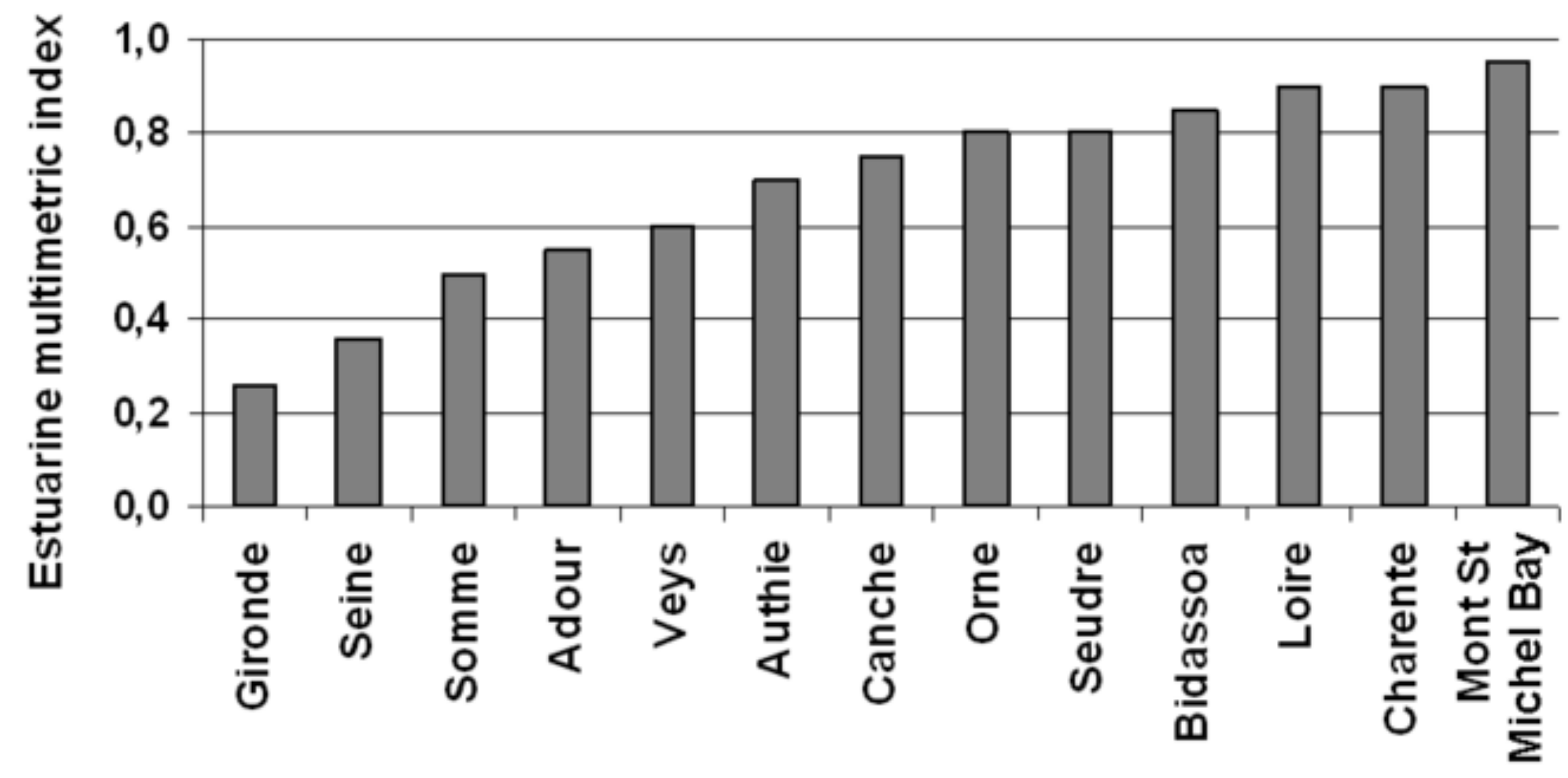


Click here to download high resolution image

Author-produced version of the article published in Marine Pollution Bulletin, 2010, vol. 60, n 6, p. 908 - 918 The original publication is available at http://www.sciencedirect.com/ doi : 10.1016/j.marpolbul.2010.01.001

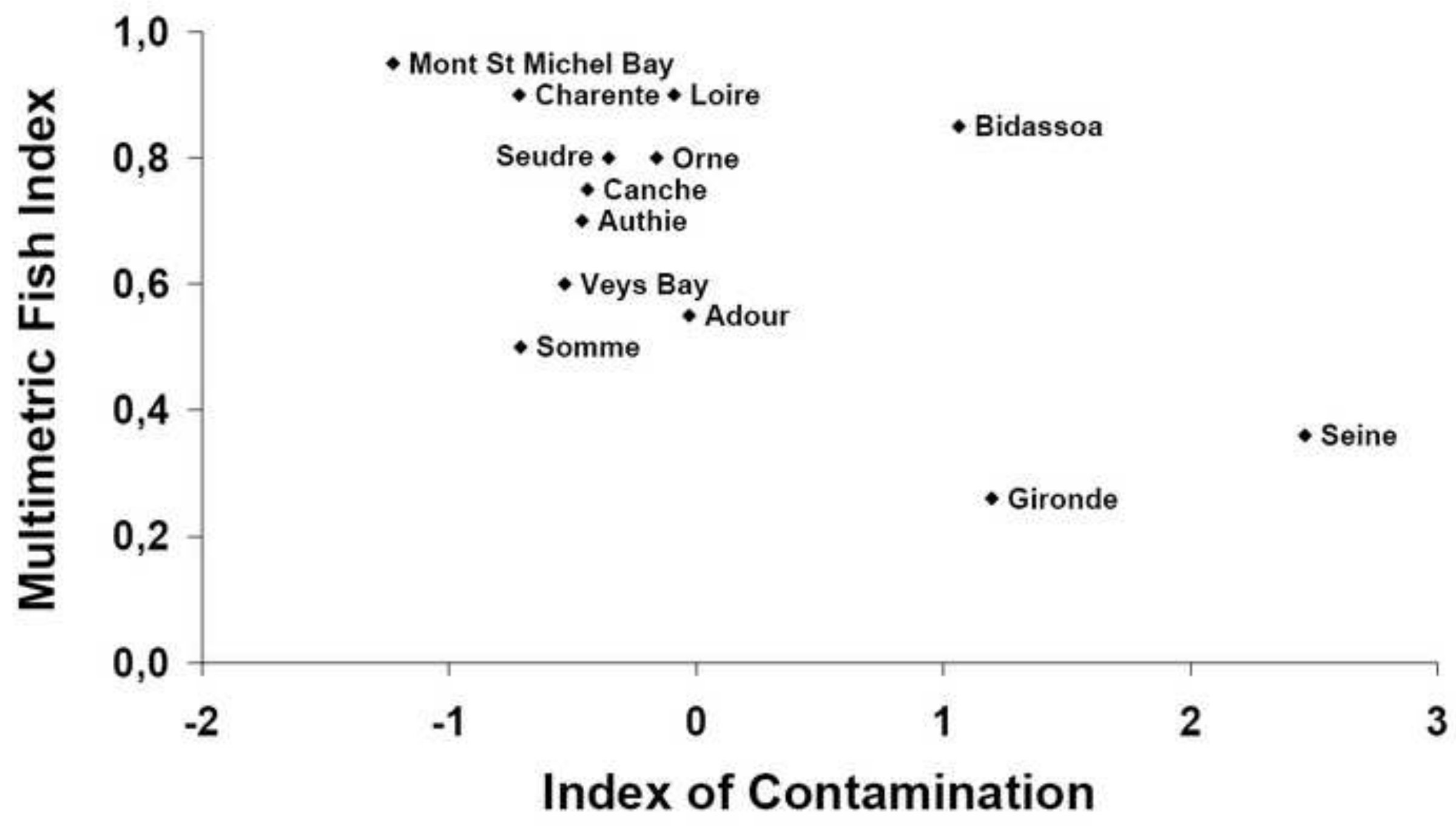

